\title{
S100A8-targeting siRNA enhances arsenic trioxide-induced myeloid leukemia cell death by down-regulating autophagy
}

\author{
LIANGCHUN YANG, MINGHUA YANG, HONG ZHANG, ZHUO WANG, YAN YU, \\ MIN XIE, MINGYI ZHAO, LIYING LIU and LIZHI CAO
}

\author{
Department of Pediatrics, Xiangya Hospital, Central South University, Changsha, Hunan 410008, P.R. China
}

Received July 22, 2011; Accepted September 8, 2011

DOI: $10.3892 / \mathrm{ijmm} .2011 .806$

\begin{abstract}
Chemoresistance has become a major obstacle to the successful treatment of leukemia. Autophagy, a regulated process of degradation and recycling of cellular constituents, has recently caught increasing attention for its roles in conferring resistance to various commonly used anticancer therapies. Here we showed that the member of the S100 calcium-binding protein family, $\mathrm{S} 100 \mathrm{~A} 8$, is a critical regulator of chemoresistance in the autophagy process. It positively correlated with the clinical status in childhood acute myeloblastic leukemia (AML) and it was released from leukemia cells after chemotherapy-induced cytotoxicity. Knockdown of S100A8 expression increased the sensitivity of leukemia cells to chemotherapy and apoptosis. Moreover, suppressing S100A8 expression decreased autophagy as evaluated by the increased expression of the autophagic marker microtubuleassociated protein light chain 3 (LC3)-II, degradation of SQSTM1/Sequestosome 1 (p62) and formation of autophagosomes. Furthermore, stimuli that enhanced reactive oxygen species (ROS) promoted cytosolic translocation of S100A8 and thereby enhanced autophagy. S100A8 directly interacted with the autophagy protein Beclin1 displacing Bcl-2. These results suggest that $\mathrm{S} 100 \mathrm{~A} 8$ is a critical pro-autophagic protein that enhances cell survival and regulates chemoresistance in leukemia cells likely through disassociating the Beclin1-Bcl-2 complex.
\end{abstract}

\section{Introduction}

Autophagy is a highly evolutionarily conserved catabolic mechanism responsible for the removal and breakdown of cellular material as a mean to maintain intracellular homeostasis $(1,2)$. During this process, cytosolic constituents are sequestered into autophagosomes, which subsequently fuse

Correspondence to: Professor Lizhi Cao, Department of Pediatrics, Xiangya Hospital, Central South University, 110 Xiangya Road Changsha, Hunan 410008, P.R. China

E-mail: caolizhi318@gmail.com

Key words: S100A8, leukemia, autophagy, drug resistance, reactive oxygen species, Beclin1, Bcl-2 with lysosomes to become autolysosomes where their contents are degraded (3). Many clinically available cancer therapeutics, including DNA-damaging chemotherapeutics, radiation therapy and molecular targeted therapies have been found to induce autophagy in cell culture and animal models (4-6). However, the role of autophagy in response to chemoresistance in leukemia cells is not clearly defined.

S100A8 (also designated MRP8 or calgranulin A) is a member of the S100 multigene subfamily of cytoplasmic EF-hand $\mathrm{Ca}^{2+}$-binding proteins (7). At least 16 genes of the S100 family, including the gene coding for S100A8, are clustered on human chromosome 1q21, a frequent target region for chromosomal rearrangements that occur during tumor development (8). S100A8 is differentially expressed in a wide variety of cell types and is abundant in myeloid cells $(9,10)$. It has been reported to regulate cell proliferation and metastatic processes (11-13), to induce apoptosis $(14,15)$ and to be involved in the progression of various cancers $(16,17)$.

Research has shown that S100A8/S100A9 (exogenous purified protein) induces autophagy and promotes cell death (18). However, whether endogenous S100A8 regulates autophagy and influences chemotherapy sensitivity in myelogenous leukemia cells remains unknown. In this study, the expression of S100A8 in childhood acute leukemia, the involvement of S100A8 in autophagy, its relation with reactive oxygen species (ROS) generation, its effect on the Beclin1-Bcl-2 complex and its influence on chemoresistance of leukemia cells were investigated collectively, which would help obtain more insight into S100A8's function in regulating autophagy and chemoresistance of leukemia cells.

\section{Materials and methods}

Reagents. The antibodies to S100A8, Fibrillarin and SOD1 were obtained from Abcam (USA). The antibodies to LC3, Beclin1, Bcl-2 and actin were obtained from Cell Signaling Technology (USA). The antibody to p62 was obtained from Santa Cruz Biotechnology (USA). Vincristine (VCR), adriamycin (ADM), arsenic trioxide $\left(\mathrm{As}_{2} \mathrm{O}_{3}\right)$, rotenone (Rot), thenoyltrifluoroacetone (TTFA), antimycin A (AA), E64D and pepstatin were from Sigma (USA).

Human S100A8-siRNA and human SOD1-siRNA were obtained from Gene Pharma Co., Ltd. (Shanghai, China). ROS activity assay kit, FITC Annexin V Apoptosis Detection kit 
and the Nuclear and Cytoplasmic Protein Extraction kit were purchased form Beyotime Institute of Biotechnology (Beijing, China).

Cell culture. Acute promyelocytic leukemia HL-60 and chronic myelogenous leukemia K562 cells (Xiangya School of Medicine Type Culture Collection, China) were cultured in RPMI-1640 medium with $10 \%$ heat-inactivated fetal bovine serum (FBS), in $5 \% \mathrm{CO}_{2}$ and $95 \%$ air.

Patients and cell separation. Diagnostic childhood acute myeloblastic leukemia (AML) and acute lymphoblastic leukemia (ALL) bone marrow samples were obtained after informed consent and with the approval of the Research Ethics Committee at Central South University. The diagnoses of AML and ALL were based on morphology and flow cytometric analysis of immunophenotype. Bone marrow mononuclear cells (BMMCs) were isolated by Ficoll density gradient centrifugation.

Small interfering RNA (siRNA) transfection. Human S100A8siRNA and human SOD1-siRNA were transfected into cells using Lipofectamine RNAiMAX reagent according to the manufacturer's instructions (Invitrogen, USA). After $3 \mathrm{~h}$ incubation, the medium was replaced with RPMI-1640 containing $20 \%$ FBS and the cells were incubated for another $48 \mathrm{~h}$ at $37^{\circ} \mathrm{C}$. After siRNA transfection for $48 \mathrm{~h}$, the cell medium was changed before subsequent treatments.

Cell viability assay. Cell viability was assessed by the MTT assay (19). Cells were plated in 96-well flat bottom tissue culture plates at a density of $\sim 5 \times 10^{5}$ cells/well. After the treatment, $20 \mu 1$ of $5 \mathrm{mg} / \mathrm{ml}$ MTT (in PBS) was added to each well of a $96-w e l l$ plate, and continually incubated $4 \mathrm{~h}$ at $37^{\circ} \mathrm{C}$. The formazan granules obtained in cells were then dissolved in $150 \mu 1$ dimethyl sulfoxide (DMSO). The absorbance values were detected at a wavelength of $490 \mathrm{~nm}$ by a 96-well multiscanner autoreader (Thermo, USA). The experiments were performed 3 times. Cell viability was calculated as $\%=(\mathrm{OD}$ of treated cells/OD of control cells) x 100.

ELISA for S100A8 measurement. Quantitative evaluation of S100A8 in cell culture supernatants was performed by ELISA. Briefly, leukemia cells were cultured in 6-well plates. The supernatants were collected $48 \mathrm{~h}$ later and the concentration of secreted S1008A proteins was determined using an ELISA kit (Beyotime). Plates were read in an ELISA microplate reader (Thermo) at $450 \mathrm{~nm}$. The experiments were performed 3 times.

Electron microscopy. Leukemia cells were collected and fixed in 2.5\% glutaraldelhyde for at least $3 \mathrm{~h}$. Then cells were treated with $2 \%$ paraformaldehyde at room temperature for $60 \mathrm{~min}, 0.1 \%$ glutaraldelhyde in $0.1 \mathrm{M}$ sodium cacodylate for $2 \mathrm{~h}$, post-fixed with $1 \% \mathrm{OsO}_{4}$ for $1.5 \mathrm{~h}$, after second washing, dehydrated with graded acetone, and embedded in Quetol 812. Ultrathin sections were observed using a Hitachi H7500 electron microscope (Tokyo, Japan).

Reverse transcription PCR (RT-PCR). Total-RNA was isolated from BMMCs using TRIzol reagent (Invitrogen) according to the manufacturer's protocol. RNA concentration and purity were measured with a spectrophotometer at A260 and A260/280, respectively. RNA was reversetranscribed into cDNA using a Primescript ${ }^{\mathrm{TM}}$ RT reagent kit (Invitrogen) according to the manufacturer's instructions. The sequences of primers used were as follows: for $\beta$-actin, forward, 5'-TCCTTCCTGGGCATGGAGTC-3' and reverse, 5'-GTAACGCAACTAAGTCATAGTC-3'; for S100A8, forward, 5'-TGTCAGCTGTCTTTCAGAAG-3' and reverse, 5 '-ACGCCCATCTTTATCACCAG-3'. $\beta$-actin was used as an internal control to evaluate the relative expressions of S100A8. The polymerase chain reaction (PCR) conditions were as follows: denaturation at $94^{\circ} \mathrm{C}$ for $2 \mathrm{~min}$, followed by 30 cycles of $94^{\circ} \mathrm{C}$ for $30 \mathrm{sec}, 55^{\circ} \mathrm{C}$ for $30 \mathrm{sec}\left(\beta\right.$-actin, $51^{\circ} \mathrm{C}$ for $\left.30 \mathrm{sec}\right)$, $72^{\circ} \mathrm{C}$ for $30 \mathrm{sec}$, and a 5 min elongation at $72^{\circ} \mathrm{C}$. PCR products were analyzed with $1.0 \%$ agarose gel electrophoresis. The gels were stained with EB, photographed and scanned using Band Leader software for grey scale semi-quantitative analysis.

Western blotting analysis. Western blotting was performed with various targeted primary antibodies and horseradish peroxidase-conjugated AffiniPure secondary antibodies. $\beta$-actin [goat anti-rabbit $\operatorname{IgG}(1: 1,000$, polyclonal antibody, CST, USA)] served as a control protein. In brief, leukemia cells with different treatments were collected and lysed. The whole cells lysate was separated by $8 \%$ (10,12 and 15\%) SDS-PAGE and electrophoretically transferred onto polyvinylidene difluoride (PVDF) blotting membrane (Beyotime). The membrane was blocked with $5 \%$ non-fat dry milk in TBST $(50 \mathrm{mM}$ Tris $\mathrm{pH} 7.5,100 \mathrm{mM} \mathrm{NaCl}, 0.15 \%$ Tween-20), incubated with the primary antibodies (at various dilutions) for $12 \mathrm{~h}$ at $4^{\circ} \mathrm{C}$, and washed three times with TBST for $10 \mathrm{~min}$. The membranes were then incubated for $12 \mathrm{~h}$ at $4^{\circ} \mathrm{C}$ temperature with secondary antibodies and detected with ECL reagent (Pierce, USA) after three washes with TBST for $10 \mathrm{~min}$. Membranes were exposed to X-ray film and the expressions of the targeted proteins were quantified by detecting the specific band recorded on X-ray film. BandScan 5.0 system was used to quantify and analyze each specific band obtained after Western blotting.

Immunoprecipitation analysis. Cells were lysed at $4^{\circ} \mathrm{C}$ in ice-cold lysis buffer $(50 \mathrm{mM}$ Tris-HCl, $\mathrm{pH}$ 7.4, containing $150 \mathrm{mM} \mathrm{NaCl}, 1 \%$ NP-40, $0.5 \%$ Na-deoxycholate, $0.1 \%$ SDS, protease inhibitors cocktail), and cell lysates were cleared by a brief centrifugation $(12,000 \mathrm{x} \mathrm{g}, 10 \mathrm{~min})$. Concentrations of proteins in the supernatant were determined by the BCA assay. Before immunoprecipitation, samples containing equal amount of proteins were pre-cleared with protein $\mathrm{A}$ or protein $\mathrm{G}$ agarose/sepharose (Santa Cruz Biotechnology) $\left(4^{\circ} \mathrm{C}\right.$, $3 \mathrm{~h}$ ), and subsequently incubated with various irrelevant IgG or specific antibodies $(5 \mathrm{mg} / \mathrm{ml})$ in the presence of protein $\mathrm{A}$ or $\mathrm{G}$ agarose/sepharose beads for $2 \mathrm{~h}$ or overnight at $4^{\circ} \mathrm{C}$ with gentle shaking (20). After incubation, the agarose/sepharose beads were extensively washed with PBS, and the proteins were eluted by boiling in $2 \mathrm{X}$ SDS sample buffer before SDS-PAGE electrophoresis.

Determination of ROS generation. Changes in the intracellular levels of ROS were determined by measuring oxidative conversion of cell-permeable $2^{\prime}, 7^{\prime}$-dichlorofluorescein diacetate 


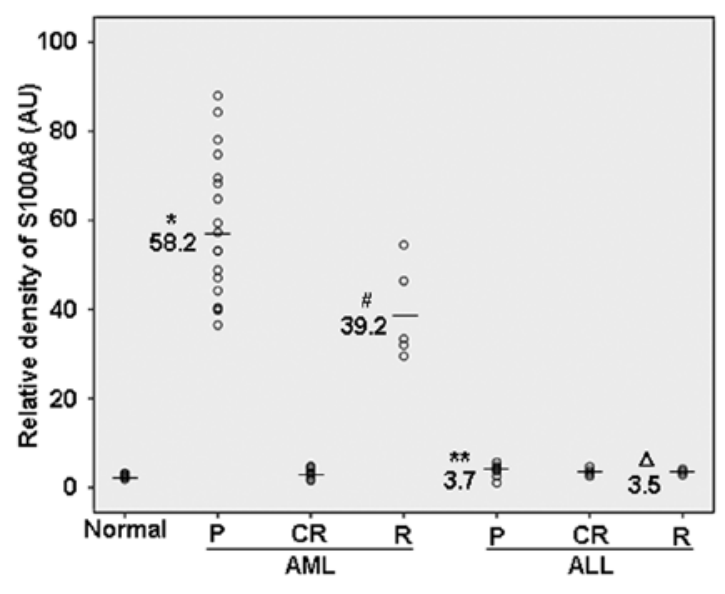

B

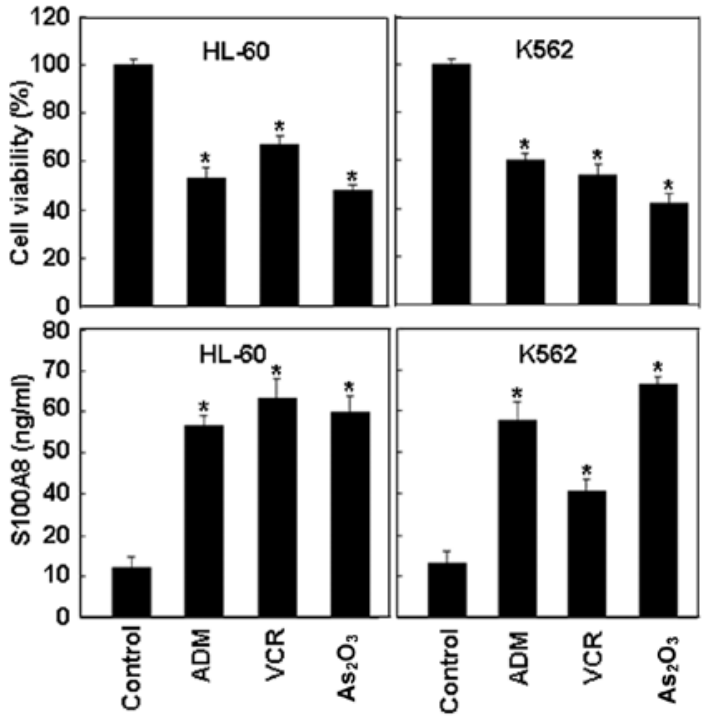

Figure 1. Correlation of S100A8 with the development of childhood AML and its release by chemotherapeutic drug treatments. (A) Relative expression levels of S100A8 in childhood leukemia. Total-mRNA was extracted from normal or patient BMMCs, and S100A8 level was determined by the relative optical intensity (in arbitrary units, AU) of the bands by RT-PCR. Each dot represents the relative S100A8 levels in each individual sample. AML, acute myeloblastic leukemia; ALL, acute lymphoblastic leukemia; $\mathrm{P}$, primary; $\mathrm{CR}$, complete remission; $\mathrm{R}$, relapse. ${ }^{*} \mathrm{P}<0.05$ vs. normal; ${ }^{*} \mathrm{P}<0.05$ vs. $\mathrm{CR} ;{ }^{* *} \mathrm{P}>0.05$ vs. normal; ${ }^{\circ} \mathrm{P}>0.05$ vs. $\mathrm{CR}$. (B) HL-60 and K562 cells were treated with adriamycin (ADM, $1 \mu \mathrm{g} / \mathrm{ml})$, vincristine (VCR, $1 \mu \mathrm{g} / \mathrm{ml})$ or arsenic trioxide (As $\left.\mathrm{O}_{3}, 5 \mu \mathrm{M}\right)$ for $24 \mathrm{~h}$, and then the cell viability (top) and S100A8 release (bottom) were analyzed ( $\mathrm{n}=3,{ }^{*} \mathrm{P}<0.05$ vs. control group). Cell viability of the control was set as $100 \%$.

(DCFH-DA) into fluorescent dichlorofluorescein (DCF) in a fluorospectrophotometer (F4000, Japan). Cells were washed with D-Hank's buffer and incubated with DCFH-DA at $37^{\circ} \mathrm{C}$ for $20 \mathrm{~min}$. Then the DCF fluorescence of 20,000 cells was detected by fluorospectrophotometer analysis at an excitation wavelength of $488 \mathrm{~nm}$ and an emission wavelength of $535 \mathrm{~nm}$. The increasing production of ROS was expressed as a percentage of control.

Apoptosis assays. Apoptosis in cells was assessed using the FITC Annexin V Apoptosis Detection kit (Annexin V-FITC, propidium iodide (PI) solution, and Annexin $\mathrm{V}$ binding buffer). This assay involves staining cells with Annexin V-FITC (a phospholipid-binding protein that binds to disrupted cell membranes) in combination with PI (a vital dye that binds to DNA penetrating into apoptotic cells). Flow cytometric analysis (FACS) was performed to determine the percentage of cells that were undergoing apoptosis (Annexin $\mathrm{V}^{+} / \mathrm{PI}$ ).

Statistical analysis. Data are expressed as the mean \pm SEM. Significance of differences between groups was determined by two-tailed Student's t-test. $\mathrm{P}<0.05$ was considered significant.

\section{Results}

Correlation of S100A8 with the development of childhood AML and its release by chemotherapeutic drug treatments. We investigated the relative S100A8 mRNA expression levels in BMMCs obtained from 31 patients with AML (18 patients in primary, 5 in relapse, and 8 in complete remission phase) and 14 patients with ALL (7 patients in primary, 3 in relapse, and 4 in complete remission phase). Higher levels of S100A8 were found in BMMCs derived from patients with primary and relapse leukemia compared with the normal healthy subjects, or patients with complete remission in AML patients (Fig. 1A). The expression levels of S100A8 in ALL patients didn't significantly differ between primary or relapse patients and the normal healthy subjects or complete remission patients (Fig. 1A). It is suggested that S100A8 may be correlated with the clinical status in childhood AML.

To further determine the potential role of S100A8 in leukemia, we quantified S100A8 in culture supernatants of leukemia cells following treatment with several chemotherapeutic drugs, such as vincristine (VCR, $1 \mu \mathrm{g} / \mathrm{ml}$ ), adriamycin (ADM, $1 \mu \mathrm{g} / \mathrm{ml}$ ), and arsenic trioxide $\left(\mathrm{As}_{2} \mathrm{O}_{3}, 5 \mu \mathrm{M}\right)(21)$, which are widely used for the treatment of hematological malignancies. HL-60 and K562 cells were treated with chemotherapeutic drugs (VCR, ADM and $\mathrm{As}_{2} \mathrm{O}_{3}$ ) for $24 \mathrm{~h}$. Cytotoxicity of leukemia cells increased after the treatment of chemotherapeutic drugs (Fig. 1B). In HL-60 and K562 cells treated with different chemotherapeutic drugs for $24 \mathrm{~h}$, the concentration of S100A8 in the supernatants was significantly elevated compared with the untreated cells (Fig. 1B). Altogether, this data suggest that S100A8 may hold an important role in tumorigenesis.

siRNA-mediated silencing of S100A8 expression increases chemotherapy sensitivity in leukemia cells. Specific siRNA targeting of S100A8 mRNA was used to knockdown S100A8 expression. We performed Western blot analyses to examine the expression of S100A8 in leukemia cells. Transfection with S100A8 siRNA resulted in a remarkable decrease of S100A8 expression in HL-60 and K562 cells (Fig. 2A). In contrast, transfection with control siRNA did not interfere with S100A8 expression (Fig. 2A). Moreover, we found that knockdown of S100A8 in these cells increased the chemotherapy sensitivity 
A

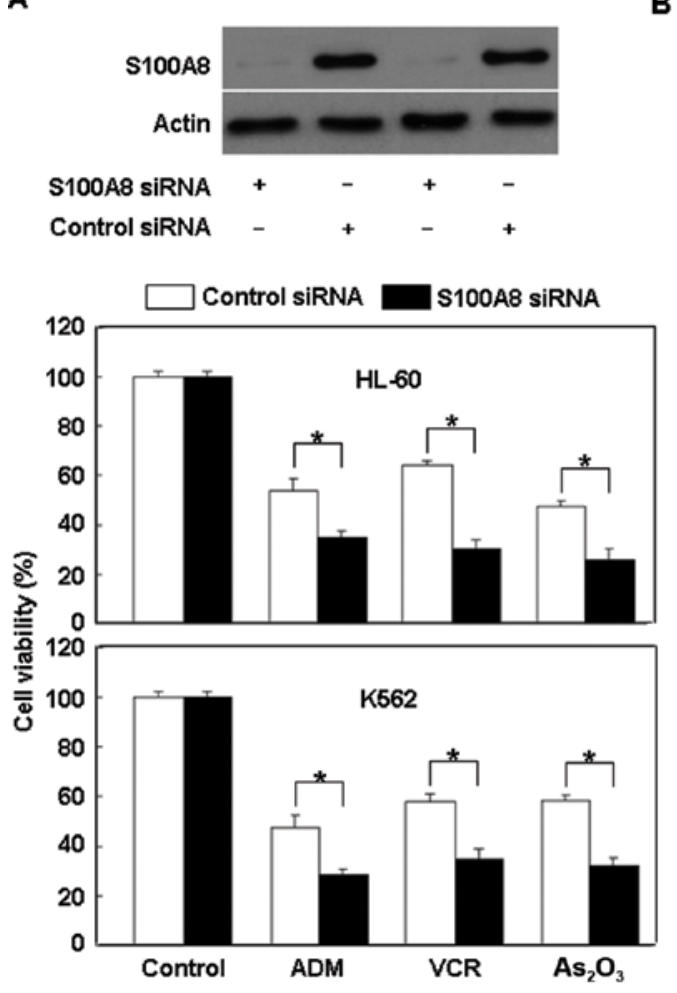

B
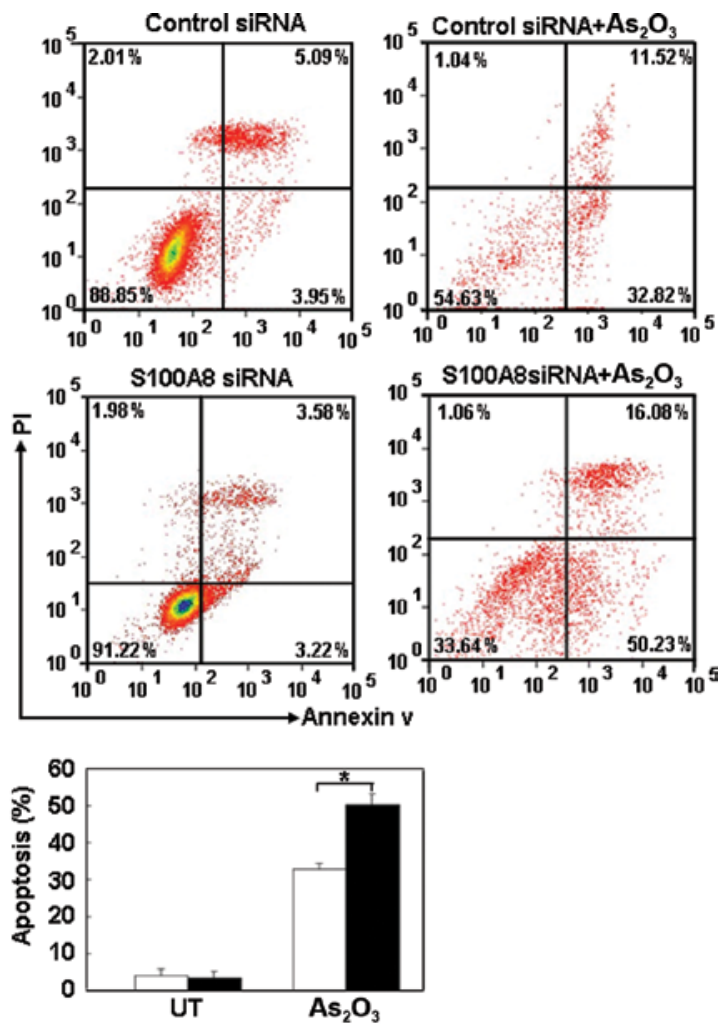

Figure 2. siRNA-mediated silencing of S100A8 expression increases chemotherapy sensitivity in leukemia cells. (A) S100A8 knockdown increased the sensitivity of leukemia cells to chemotherapy. After knockdown of S100A8 by siRNA in leukemia cells (HL-60 and K562) cells were treated with vincristine (VCR, $1 \mu \mathrm{g} / \mathrm{ml}$ ), adriamycin (ADM, $1 \mu \mathrm{g} / \mathrm{ml})$ or arsenic trioxide $\left(\mathrm{As}_{2} \mathrm{O}_{3}, 5 \mu \mathrm{M}\right)$ for $48 \mathrm{~h}$, and then the cell viability was assayed by the MTT assay ( $\mathrm{n}=3$, $\left.{ }^{*} \mathrm{P}<0.05\right)$. Cell viability of the control was set as 100\%. (B) S100A8 knockdown increased anti-cancer drug-induced apoptosis. After knockdown of S100A8 by siRNA in HL-60 cells for $48 \mathrm{~h}$ and treatment with $\mathrm{As}_{2} \mathrm{O}_{3}(5 \mu \mathrm{M})$, cell early apoptosis was examined by flow cytometry at $24 \mathrm{~h}$. $(\mathrm{n}=3$, $\mathrm{P}<0.05)$. UT, untreated group.

and early apoptosis with $\mathrm{As}_{2} \mathrm{O}_{3}$ treatment compared with the control group (Fig. 2), supporting a potential prosurvival role for S100A8 in cells exposed to chemotherapy.

Knockdown of S100A8 expression inhibits the initiation of autophagy in leukemia cells. Recently, autophagy has been shown to have important role in the mechanism of resistance to chemotherapy in hematological malignancies (22-25). The inhibition of autophagy increased anti-cancer-therapy-induced apoptosis $(26,27)$. Whether S100A8 regulates autophagy in leukemia cells, is not fully understood. Microtubuleassociated protein light chain 3 (LC3) is now widely used to monitor autophagy. During autophagy, LC3 is processed post-translationally into soluble LC3-I, and subsequently converted to membrane-bound LC3-II, which correlated with the number of autophagosomes (3). In this study, we found that classical autophagic stimuli, such as starvation (Hank's Balanced Salt Solution, HBSS) or rapamycin treatment, increased the expression of LC3-II in HL-60 cells (Fig. 3A). Similar to HBSS and rapamycin, $\mathrm{As}_{2} \mathrm{O}_{3}$ at a therapeutic dose $(5 \mu \mathrm{M})$ also increased LC3-II expression (Fig. 3A), suggesting $\mathrm{As}_{2} \mathrm{O}_{3}$-induced autophagy in leukemia cells. Furthermore, pre-treatment of HL-60 and K562 cells with S100A8 siRNA for $48 \mathrm{~h}$ and then with $\mathrm{As}_{2} \mathrm{O}_{3}$ treatment for $24 \mathrm{~h}$ significantly decreased the expression of LC3-II compared with the control groups (Fig. 3B). Meanwhile, the expression of Beclin1, which is necessary for the formation of autophagosomes during the autophagic sequestration process $(28,29)$, was detected in leukemia cells. Here, we found that knockdown of S100A8 expression and then treatment with $\mathrm{As}_{2} \mathrm{O}_{3}$ for $24 \mathrm{~h}$ significantly decreased Beclin1 expression compared with the control siRNA group (Fig. 3B). In addition, its expression was correlated well with both S100A8 and LC3-II expressions in leukemia cells.

Protein degradation by autophagy is an important mechanism to mitigate the accumulation of polyubiquitinated protein aggregates. The polyubiquitin-binding protein SQSTM1/ aequestosome 1 (p62) is degraded by autophagy $(30,31)$. p62 has LC3 binding domains, which target this protein for incorporation into the autophagosomes thus serving as a selective substrate of autophagy (30). To investigate whether S100A8 is a direct activator of autophagic flux, we evaluated the expression of p62 in this study. Knockdown of S100A8 decreased LC3-II protein levels, but increased p62 expression compared with the control group in $\mathrm{K} 562$ cells, indicating that p62 degradation is dependent on S100A8-induced autophagy (Fig. 3C). Moreover, treatment with the lysosomal protease inhibitors pepstatin and E64D (32) increased LC3-II and p62 expressions compared with the S100A8 siRNA group (Fig. 3C). These results suggest that observed increase in LC3-II was not due to decreased degradation of lipidated LC3, but was a result of the increased autophagic flux.

Our evidence for $\mathrm{As}_{2} \mathrm{O}_{3}$-induced autophagy was further substantiated by electron microscopy, the most convincing and standard method to detect autophagy (3), which revealed the presence of multiple autophagosome-like vacuoles with 
A

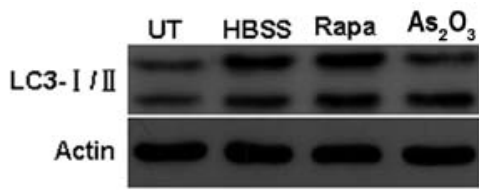

B

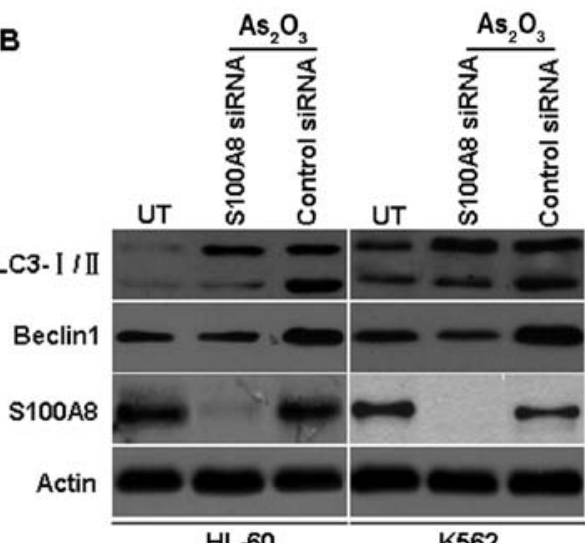

C

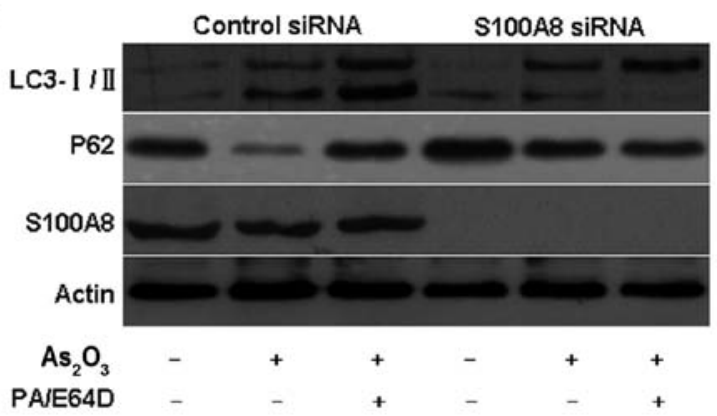

D

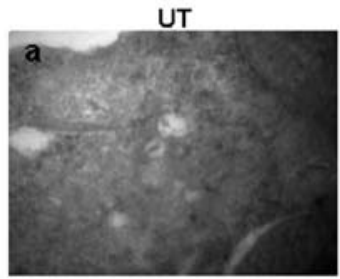

Control siRNA+ $\mathrm{As}_{2} \mathrm{O}_{3}$

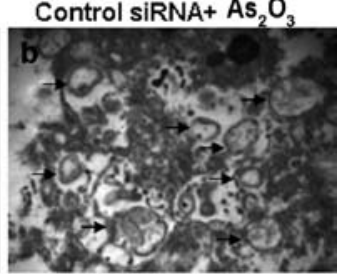

S100A8 SiRNA+ $\mathrm{As}_{2} \mathrm{O}$

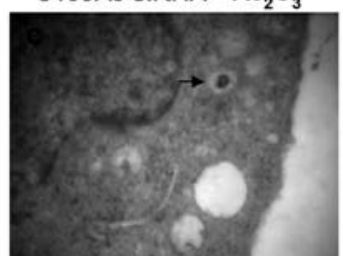

Figure 3. Knockdown of S100A8 expression inhibits the initiation of autophagy in leukemia cells. (A) $\mathrm{As}_{2} \mathrm{O}_{3}$ induced the initiation of autophagy. Western blotting showing the LC3-I/II expression levels in HL-60 cells treated with Hank's Balanced Salt Solution (HBSS) for $2 \mathrm{~h}$, rapamycin (Rapa, $100 \mathrm{nM}$ ) for $24 \mathrm{~h}$ and $\mathrm{As}_{2} \mathrm{O}_{3}(5 \mu \mathrm{M})$ for $24 \mathrm{~h}$. UT, untreated group. (B) HL-60 and K562 cells were pre-treated with S100A8 RNA interference for $48 \mathrm{~h}$, and then treated with $\mathrm{As}_{2} \mathrm{O}_{3}(5 \mu \mathrm{M})$ for $24 \mathrm{~h}, \mathrm{LC} 3-\mathrm{I} / \mathrm{II}$ and Beclin1 levels were assayed by Western blot analysis. UT, untreated group. (C) HL-60 cells were transfected with S100A8 siRNA, then pre-treated for $1 \mathrm{~h}$ with pepstatin $\mathrm{A}(\mathrm{PA}, 10 \mu \mathrm{M})$ and E64D $(10 \mu \mathrm{M})$ as indicated, and were subsequently treated for $24 \mathrm{~h}$ with $\mathrm{As}_{2} \mathrm{O}_{3}(5 \mu \mathrm{M})$ in the continuous presence or absence of the inhibitors, as indicated. LC3-I/II and p62 levels were assayed by Western blot analysis. (D) Ultrastructural features in HL-60 cells with S100A8 siRNA for $\mathrm{As}_{2} \mathrm{O}_{3}$ treatment. The number of autophagosomes seen in cells treated with control siRNA plus As $\mathrm{O}_{3}(5 \mu \mathrm{M}, 24 \mathrm{~h})$ was higher compared with cells treated with S100A8 siRNA plus $\mathrm{As}_{2} \mathrm{O}_{3}$. Arrows, autophagosomes; magnification, x20,000; UT, untreated group.

double-membrane structures in the control siRNA group compared with the S100A8 siRNA group (Fig. 3D). Altogether, these data demonstrate that leukemia cells show typical autophagy reactions to $\mathrm{As}_{2} \mathrm{O}_{3}$, and $\mathrm{S100A8}$ is required for the initiation of autophagy in leukemia cells.

Reactive oxygen species-dependent signals enhance autophagy and regulate $\mathrm{S} 100 \mathrm{~A} 8$ translocation. $\mathrm{As}_{2} \mathrm{O}_{3}$ has important antileukemic effects in vitro and in vivo, and is known to mediate its effects via its ability to induce apoptosis (33). A key mechanism for such induction of apoptosis is the generation of ROS, resulting in the induction of proapoptotic signals and engagement of the casepase cascade (33). Autophagy and apoptosis are now regarded as different aspects of the same cell death continuum (34) and increasing evidence demonstrates that ROS also induces autophagy (35). In this study, we have found that leukemia cells treated with $\mathrm{As}_{2} \mathrm{O}_{3}$ induced autophagy, and S100A8 regulated the initiation of autophagy (Fig. 3). Here, we found that $\mathrm{As}_{2} \mathrm{O}_{3}$ induced ROS generation, and knockdown of S100A8 decreased ROS expression (Fig. 4A). Whether ROS generation regulates autophagy and affected S100A8 expression in leukemia cells remains unclear.

The mitochondria electron transport chain (mETC) complexes are the major generator of ROS in cells and tissues (35). To evaluate the relationship between mitochondrial ROS production and initiation of autophagy, we treated HL-60 cells with different mETC inhibitors. HL-60 cells treated with rotenone (Rot; complex I inhibitor), thenoyltrifluoroacetone (TIFA; complex II inhibitor), and antimycin A (AA; complex III inhibitor) increased ROS production and LC3-II expression (Fig. 4B). These mETC inhibitors also induced S100A8 translocation from the nucleus to the cytosol, as assessed by Western blotting of subcellular fractions (Fig. 4C). As a protective strategy of cells or tissues against oxidative stress, the superoxide dismutase (SOD) family members, catalase, or glutathione peroxidase clear ROS under physiological conditions (35). We found that knockdown of SOD1 increased $\mathrm{As}_{2} \mathrm{O}_{3}$-induced autophagy and S100A8 translocation in K562 cells (Fig. 4D). Together, these results demonstrate that ROS signals are required for sustained autophagy and S100A8 translocation.

Depletion of S100A8 promotes persistent Beclin1-Bcl-2 interaction. The interaction between Bcl-2 and Beclin1 is an important molecular event during autophagy (36). The disassociation of Beclin1-Bcl-2 complex sustains autophagy (36). Thus, we determined the effect of S100A8 on the interaction between Beclin1 and Bcl-2. Knockdown of S100A8 blocked the disassociation of Beclin1-Bcl-2 in the setting of enhanced autophagy (Fig. 5A), further supporting that $\mathrm{S} 100 \mathrm{~A} 8$ regulates $\mathrm{As}_{2} \mathrm{O}_{3}$-induced 
A

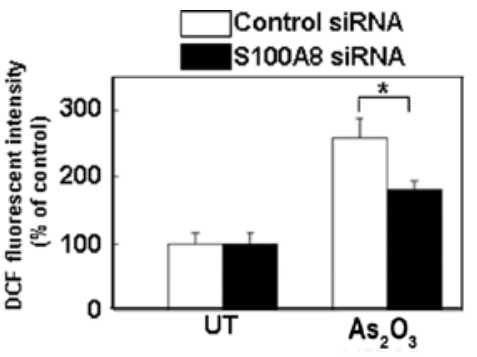

B
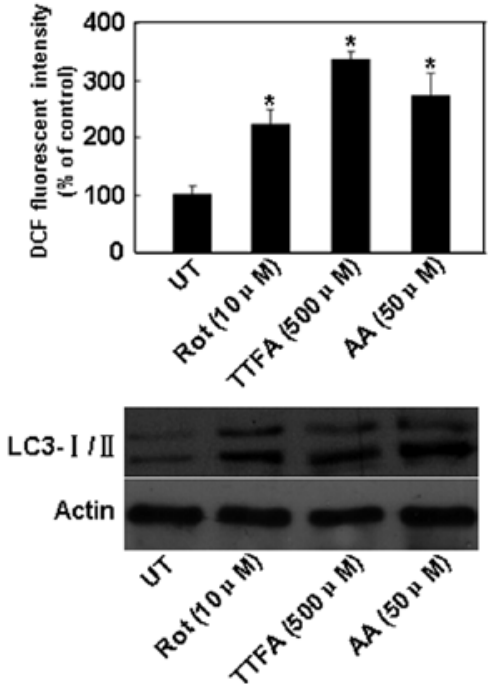

C

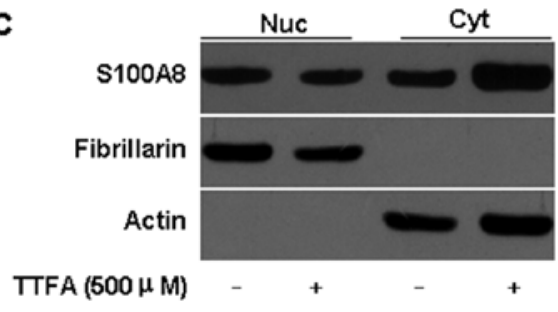

D

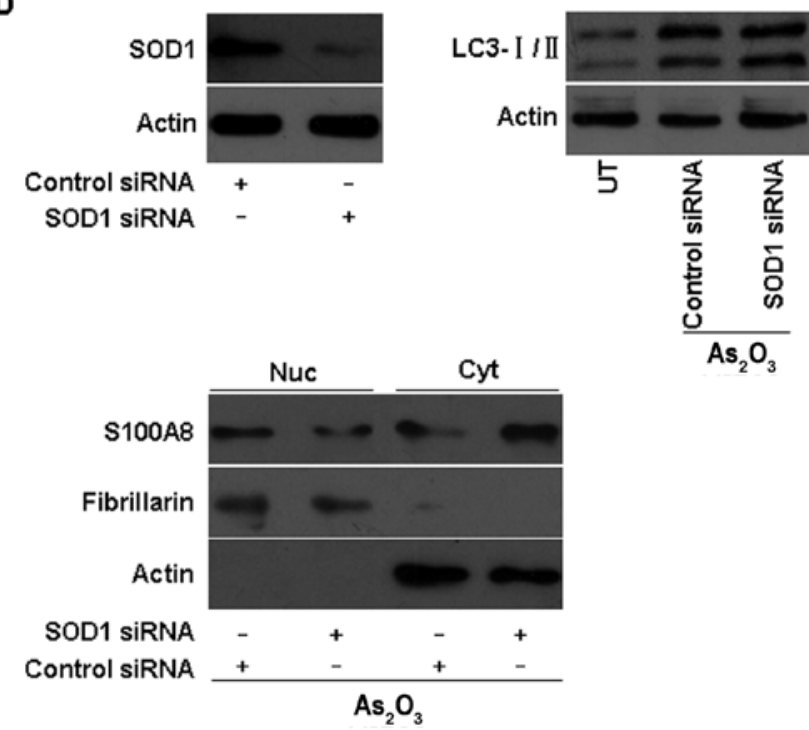

Figure 4. Reactive oxygen species (ROS)-dependent signals enhance autophagy and regulate the S100A8 translocation. (A) Knockdown of S100A8 limits $\mathrm{As}_{2} \mathrm{O}_{3}$-induced ROS production. HL-60 cells were transfected with S100A8 siRNA for $48 \mathrm{~h}$, and then treated with $\mathrm{As}_{2} \mathrm{O}_{3}$ for $24 \mathrm{~h}$. ROS production was assessed by measuring the fluorescence intensity of DCF in a fluorescence plate reader. The increasing production of ROS was expressed as a percentage of control. ( $\mathrm{n}=3,{ }^{*} \mathrm{P}<0.05$ ). UT, untreated group. (B) mECT inhibitors promote ROS production and autophagy. HL-60 cells were stimulated with rotenone (Rot), thenoyltrifluoroacetone (TTFA), and antimycin A (AA) at the indicated doses for $12 \mathrm{~h}$. ROS production was assessed by measuring the fluorescence intensity of DCF in a fluorescence plate reader and LC3-I/II expression level was assayed by Western blot analysis. The increasing production of reactive oxygen species was expressed as a percentage of control. ( $\mathrm{n}=3, \mathrm{P}<0.05$ vs. the untreated group). UT, untreated group. (C) mECT inhibitors promote S100A8 translocation. HL-60 cells were treated with TTFA $(500 \mu \mathrm{M})$ for $24 \mathrm{~h}$, and the nuclear/cytosolic S100A8 expression was assayed by Western blot analysis. Fibrillarin is a nuclear fraction control, and actin is a cytoplasmic fraction control. Nuc, nuclear; Cyt, cytosolic. (D) SOD1 RNAi limits $\mathrm{As}_{2} \mathrm{O}_{3}$-induced autophagy and S100A8 translocation. HL-60 cells were pre-treated with SOD1 siRNA for $48 \mathrm{~h}$. Then cells were treated with $\mathrm{As}_{2} \mathrm{O}_{3}$ for $24 \mathrm{~h}$, the nuclear/cytosolic S100A8 expression and LC3-I/II expression were assayed by Western blot analysis. Nuc, nuclear; Cyt, cytosolic; UT, untreated group.

A

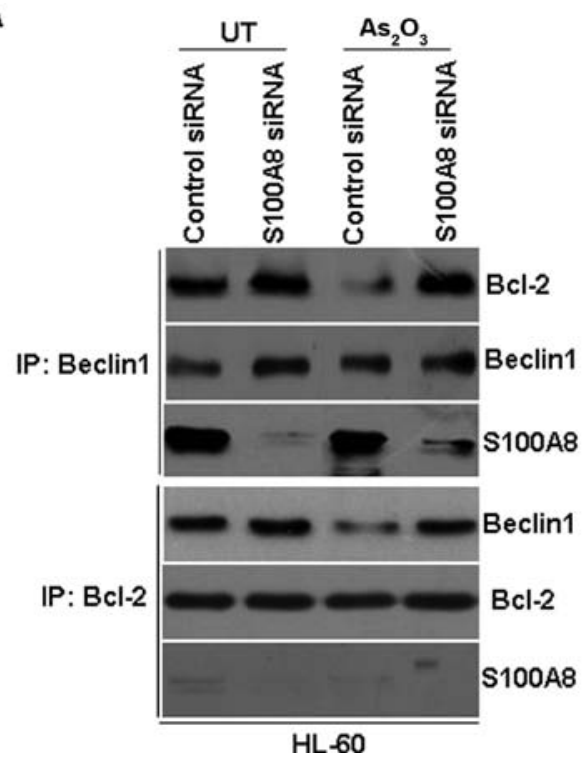

B

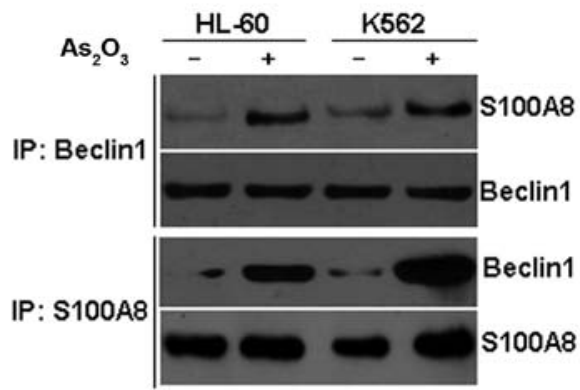

Figure 5. Depletion of S100A8 promotes persistent Beclin1-Bcl-2 interaction. (A) Knockout of S100A8 limits the disassociation of the Bcl-2-Beclin1 complex during treatment with autophagic stimuli. HL-60 cells were transfected with S100A8 siRNA for $48 \mathrm{~h}$ and then treated with As $\mathrm{O}_{3}$ for $24 \mathrm{~h}$. Protein expression levels were then assayed as indicated by co-IP or Western blotting. UT, untreated group. (B) S100A8 interacts directly with Beclin1 during autophagy. HL-60 and $\mathrm{K} 562$ cells were treated with $\mathrm{As}_{2} \mathrm{O}_{3}$ for $24 \mathrm{~h}$ and then assayed for protein expression levels as indicated by co-IP or Western blotting. 
autophagy. Meanwhile, we found that S100A8 interacted with Beclin1 but not Bcl-2 in the regulation of autophagy (Fig. 5A). Moreover, S100A8 interacted with Beclin1 in leukemia cells treated with $\mathrm{As}_{2} \mathrm{O}_{3}$ compared with the untreated group (Fig. 5B). Thus, the mechanism of the $\mathrm{S} 100 \mathrm{~A} 8$ regulation of autophagy may be exerted via the inhibition of the interaction between Beclin1 and Bcl-2.

\section{Discussion}

Autophagy is an evolutionarily conserved lysosomal selfdigestion process essential for cellular homeostasis and survival. The role of autophagy in tumor cells is not well characterized, particularly for chemotherapy. In this study, we demonstrate that a novel function of S100A8 is to affect chemotherapy sensitivity by sustaining autophagy in myeloid leukemia cells.

$\mathrm{As}_{2} \mathrm{O}_{3}$ is a metalloid that has attracted worldwide interest because it exhibits potent antineoplastic effects in vitro and in vivo (33). It shows substantial anticancer activity in patients with acute promyelocytic leukemia (APL) and other solid tumors (37-40). However, chemoresistance has become a major obstacle to successfully treat leukemia. Various mechanisms of drug resistance have been proposed so far, but an exact mechanism has still not been established (41). A detailed understanding of the mechanisms that are clinically relevant in leukemia may help predict and overcome drug resistance thereby improving chemotherapy and ultimately the outcome of cancer patients.

Our experimental data suggest that S100A8 may be involved into the mechanism of myeloid leukemia chemoresistance. Concerning the S100A8 protein, Cui et al (42) have described the use of S100A8 to discern AML differentiation and to distinguish AML from ALL. The expression of S100A8 in AML patients has been associated with worse prognosis and is a predictor of poor survival (43). In this study, we found that S100A8 expression was positively correlated with the clinical status in childhood AML. Meanwhile, depletion of S100A8 increased chemotherapy sensitivity and the apoptosis of leukemia cells. This clearly suggests a strong influence of S100A8 on chemoresistance of leukemia cells.

Autophagy is a cell death mechanism distinct from apoptosis, involving autophagosomic/lysosomal degradation of cell components (44). Depending on the cellular context or initiating stimulus, autophagy may act as protective opposing effects and promote generation of antineoplastic responses $(45,46)$. Many studies have demonstrated that inhibition of autophagy potentiates chemotherapy-induced cell death in leukemia cells $(24,25)$. However, little is known about the regulation of autophagy and chemoresistance by S100A8 in leukemia cells. Here, we found that $\mathrm{As}_{2} \mathrm{O}_{3}$ treatment of leukemia cells induced autophagy, and knockdown of S100A8 decreased the LC3 conversion (LC3-I to LC3-II), degradation of p62 and maturation of autophagosomes. This revealed a dominating role of S100A8 in regulating autophagy.

ROS function as signaling molecules in various pathway regulating both cell survival and cell death. They can be induced by many chemotherapeutic drugs (such as ADM, $\mathrm{As}_{2} \mathrm{O}_{3}$ ) and radiation therapy during cancer therapy $(47,48)$. ROS can induce autophagy through several distinct mecha- nisms involving catalase activation of Atg4 and disturbance in the mETC (35). In this study, we found that ROS generated during $\mathrm{As}_{2} \mathrm{O}_{3}$ treatment serve as signaling molecules that initiate autophagy. Importantly, this stimulus caused S100A8 cytosolic localization, suggesting that the localization of S100A8 is necessary to enhance autophagy. Moreover, we have demonstrated that S100A8 translocation in autophagy is ROS dependent.

S100A8 potentially confers its pro-autophagic activities by controlling Beclin1-Bcl-2 complex formation. The dissociation of Bcl-2 from Beclin1 is an important mechanism involved in activating autophagy after physiological stimuli (36). We found that S100A8 disrupts the interaction between Beclin1 and Bcl-2 by competitively binding to Beclin1 after $\mathrm{As}_{2} \mathrm{O}_{3}$ treatment, but not to $\mathrm{Bcl}-2$. It suggests that Beclin1-Bcl-2 complex disassociation is an important mechanism of S100A8 regulated autophagy.

In summary, we found that S100A8 reflected the stage of leukemia, influenced chemotherapy sensitivity and acted as a positive regulator of autophagy, which enhanced chemoresistance of leukemia cells. In the $\mathrm{As}_{2} \mathrm{O}_{3}$-treated cell model, ROS generated by cellular stress promoted S100A8 translocation to the cytosol, which induced autophagy and disrupted Beclin1-Bcl-2 complex formation. In light of the therapeutic promise of autophagy inhibitors to render tumor cells more susceptible to conventional therapies, our discovery that S100A8 is an important regulator of autophagy in leukemia cells may lead to the development of novel strategies for the treatment of human leukemia.

\section{Acknowledgements}

This study was supported by grants from The National Natural Sciences Foundation of China (81100359 to M.Y.).

\section{References}

1. Codogno P and Meijer AJ: Autophagy and signaling: their role in cell survival and cell death. Cell Death Differ 12: 1509-1518, 2005.

2. Levine B and Kroemer G: Autophagy in the pathogenesis of disease. Cell 132: 27-42, 2008.

3. Mizushima N, Yoshimori T and Levine B: Methods in mammalian autophagy research. Cell 140: 313-326, 2010.

4. White E and DiPaola RS: The double-edged sword of autophagy modulation in cancer. Clin Cancer Res 15: 5208-5216, 2009.

5. Liu L, Yang M, Kang R, et al: DAMP-mediated autophagy contributes to drug resistance. Autophagy 7: 112-114, 2010.

6. Wang J, Lian H, Zhao Y, Kauss MA and Spindel S: Vitamin D3 induces autophagy of human myeloid leukemia cells. J Biol Chem 283: 25596-25605, 2008.

7. Schäfer BW and Heizmann CW: The S100 family of EF-hand calcium-binding proteins: functions and pathology. Trends Biochem Sci 21: 134-140, 1996.

8. Schäfer BW, Wicki R, Engelkamp D, Mattei MG and Heizmann CW: Isolation of a YAC clone covering a cluster of nine S100 genes on human chromosome 1q21: rationale for a new nomenclature of the S100 calcium-binding protein family. Genomics 25: 638-643, 1995.

9. Foell D, Wittkowski H, Vogl T and Roth J: S100 proteins expressed in phagocytes: a novel group of damage-associated molecular pattern molecules. J Leukoc Biol 81: 28-37, 2007.

10. Kerkhoff C, Klempt $M$ and Sorg C: Novel insights into structure and function of MRP8 (S100A8) and MRP14 (S100A9). Biochim Biophys Acta 1448: 200-211, 1998.

11. Yong HY and Moon A: Roles of calcium-binding proteins, S100A8 and S100A9, in invasive phenotype of human gastric cancer cells. Arch Pharm Res 30: 75-81, 2007. 
12. Yao R, Lopez-Beltran A, Maclennan GT, Montironi R, Eble JN and Cheng L: Expression of S100 protein family members in the pathogenesis of bladder tumors. Anticancer Res 27: 3051-3058, 2007.

13. Tolson JP, Flad T, Gnau V, et al: Differential detection of S100A8 in transitional cell carcinoma of the bladder by pair wise tissue proteomic and immunohistochemical analysis. Proteomics 6: 697-708, 2006

14. Yamazaki M, Yui S and Mikami M: Purification and characterization of the cytotoxic factor in rat peritoneal exudate cells: its identification as the calcium binding protein complex, calprotectin. J Leukoc Biol 158: 307-316, 1995.

15. Yamazaki M, Yui S and Mikami M: Induction of apoptotic cell death in mouse lymphoma and human leukemia cell lines by a calcium-binding protein complex, calprotectin, derived from inflammatory peritoneal exudate cells. J Leukoc Biol 58: 650-658, 1995

16. Cross SS, Hamdy FC, Deloulme JC and Rehman I: Expression of S100 proteins in normal human tissues and common cancers using tissue microarrays: S100A6, S100A8, S100A9 and S100A11 are all overexpressed in common cancers. Histopathology 46: 256-269, 2005

17. Rafii S and Lyden D: S100 chemokines mediate bookmarking of premetastatic niches. Nat Cell Biol 8: 1321-1323, 2006.

18. Ghavaami S, Eshragi M, Ande SR, et al: S100A8/S100A9 induces autophagy and apoptosis via ROS-mediated cross-talk between mitochondria and lysosomes that involves BNIP3. Cell Res 20 : 314-331, 2010

19. Mosmann T: Rapid colorimetric assay for cellular growth and survival: application to proliferation and cytotoxicity assays. J Immunol Methods 5: 55-63, 1983.

20. Tang D, Kang R, Xiao W, Wang H, Calderwood SK and Xiao X: The anti-inflammatory effects of heat shock protein 72 involve inhibition of high-mobility-group box 1 release and proinflammatory function in macrophages. J Immunol 179: 1236-1244, 2007.

21. Kang R, Tang D, Yu Y, et al: WAVE1 regulates Bcl-2 localization and phosphorylation in leukemia cells. Leukemia 24: 177-186, 2010 .

22. Livesey KM, Tang D, Zeh HJ and Lotze MT: Autophagy inhibition in combination cancer treatment. Curr Opin Investig Drugs 10: 1269-1279, 2009.

23. Maclean KH, Dorsey FC, Cleveland JL and Kastan MB: Targeting lysosomal degradation induces p53-dependent cell death and prevents cancer in mouse models of lymphomagenesis. J Clin Invest 118: 79-88, 2008.

24. Bellodi C, Lidonnici MR, Hamilton A, et al: Targeting autophagy potentiates tyrosine kinase inhibitor-induced cell death in Philadelphia chromosome-positive cells, including primary CML stem cells. J Clin Invest 119: 1109-1123, 2009.

25. Carew JS, Nawrocki ST, Kahue CN, et al: Targeting autophagy augments the anticancer activity of the histone deacetylase inhibitor SAHA to overcome Bcr-Abl-mediated drug resistance. Blood 110: 313-322, 2007

26. Ito H, Daido S, Kanzawa T, Kondo S and Kondo Y: Radiationinduced autophagy is associated with LC3 and its inhibition sensitizes malignant glioma cells. Int J Oncol 26: 1401-1410, 2005

27. Apel A, Herr I, Schwarz H, Rodemann HP and Mayer A: Blocked autophagy sensitizes resistant carcinoma cells to radiation therapy. Cancer Res 68: 1485-1494, 2008.
28. Kihara A, Kabeya Y, Ohsumi Y and Yoshimori T: Beclinphosphatidylinositol 3-kinase complex functions at the trans-Golgi network. EMBO Rep 2: 330-335, 2001.

29. Donohue TM Jr: Autophagy and ethanol-induced liver injury. World J Gastroenterol 15: 1178-1185, 2009.

30. Pankiv S, Clausen TH, Lamark T, et al: p62/SQSTM1 binds directly to Atg8/LC3 to facilitate degradation of ubiquitinated protein aggregates by autophagy. J Biol Chem 282: 24131-24145, 2007.

31. Mathew R, Karp CM, Beaudoin B, et al: Autophagy suppresses tumorigenesis through elimination of p62. Cell 137: 1062-1075, 2009.

32. Mizushima N and T Yoshimori: How to interpret LC3 immunoblotting. Autophagy 3: 542-545, 2007.

33. Platanias LC: Biological responses to arsenic compounds. J Biol Chem 284: 18583-18587, 2009.

34. Thorburn A: Apoptosis and autophagy: regulatory connections between two supposedly different processes. Apoptosis 13: 1-9, 2008.

35. Scherz-Shouval $\mathrm{R}$ and $\mathrm{Z}$ Elazer: ROS, mitochondria and the regulation of autophagy. Trends Cell Biol 17: 422-427, 2007.

36. Pattingre S, Tassa A, Qu X, et al: Bcl-2 antiapoptotic protein inhibits Beclin1-dependent autophagy. Cell 122: 927-939, 2005.

37. Shen ZX, Chen GQ, Ni JH, et al: Use of arsenic trioxide $\left(\mathrm{As}_{2} \mathrm{O}_{3}\right)$ in the treatment of acute promyelocytic leukemia (APL): II. Clinical efficacy and pharmacokinetics in relapsed patients. Blood 89: 3354-3360, 1997.

38. Maeda $\mathrm{H}$, Hori $\mathrm{S}$, Nishitoh $\mathrm{H}$, et al: Tumor growth inhibition by arsenic trioxide $\left(\mathrm{As}_{2} \mathrm{O}_{3}\right)$ in the orthotopic metastasis model of androgen-independent prostate cancer. Cancer Res 61: 5432-5440, 2001.

39. Uslu R, Sanli UA, Sezgin C, et al: Arsenic trioxide-mediated cytotoxicity and apoptosis in prostate and ovarian carcinoma cell lines. Clin Cancer Res 6: 4957-4964, 2000.

40. Shen ZY, Shen J, Cai WJ, Hong C and Zheng MH: The alteration of mitochondria is an early event of arsenic trioxide induced apoptosis in esophageal carcinoma cells. Int J Mol Med 5: 155-158, 2000.

41. Ross DD: Novel mechanisms of drug resistance in leukemia. Leukemia 14: 467-473, 2000

42. Cui JW, Wang J, He K, et al: Proteomic analysis of human acute leukemia cells: insight into their classification. Clin Cancer Res 10: 6887-6896, 2004.

43. Nicolas E, Ramus C, Berthier S, et al: Expression of S100A8 in leukemia cells predicts poor survival in de novo AML patients. Leukemia 25: 57-65, 2011.

44. Kondo Y, Kanzawa T, Sawaya R and Kondo S: The role of autophagy in cancer development and response to therapy. Nat Rev Cancer 5: 726-734, 2005.

45. Vazquez-Martin A, Oliveras-Ferraros C and Menendez JA: Autophagy facilitates the development of breast cancer resistance to the anti-HER 2 monoclonal antibody trastuzumab. PLoS One 4: e6251, 2009

46. Song J, Qu Z, Guo X, et al: Hypoxia-induced autophagy contributes to the chemoresistance of hepatocellular carcinoma cells Autophagy 5: 1131-1144, 2009.

47. Lesser MP: Oxidative stress in marine environments: biochemistry and physiological ecology. Annu Rev Physiol 68: 253-278, 2006.

48. Ozben T: Oxidative stress and apoptosis: impact on cancer therapy. J Pharm Sci 96: 2181-2196, 2007. 